\title{
REFLECTION
}

\section{Organizational Leadership For Building Effective Health Care Teams}

Stepben H. Taplin, MD, MPH

Mary K. Foster, $P b D^{2}$

Stephen M. Shortell, $P b D^{3}$

'Process of Care Research Branch, Behavioral Research Program, Division of Cancer Control and Population Science, National Cancer Institute, Rockville, Maryland

${ }^{2}$ Earl G. Graves School of Business and Management, Morgan State University, Baltimore, Maryland

${ }^{3}$ School of Public Health, University of California, Berkeley, Berkeley, California

Conflicts of interest: authors report none.

\section{CORRESPONDING AUTHOR}

Stephen H. Taplin, MD, MPH

Process of Care Research Branch

Behavioral Research Program

Division of Cancer Control and Population

Science

National Cancer Institute

9609 Medical Center Dr

MSC 9761, 3E522

Bethesda, MD 20892

taplins@mail.nih.gov

\begin{abstract}
The movement toward accountable care organizations and patient-centered medical homes will increase with implementation of the Affordable Care Act (ACA). The ACA will therefore give further impetus to the growing importance of teams in health care. Teams typically involve 2 or more people embedded in a larger social system who differentiate their roles, share common goals, interact with each other, and perform tasks affecting others. Multiple team types fit within this definition, and they all need support from leadership to succeed. Teams have been invoked as a necessary tool to address the needs of patients with multiple chronic conditions and to address medical workforce shortages. Invoking teams, however, is much easier than making them function effectively, so we need to consider the implications of the growing emphasis on teams. Although the ACA will spur team development, organizational leadership must use what we know now to train, support, and incentivize team function. Meanwhile, we must also advance research regarding teams in health care to give those leaders more evidence to guide their work.
\end{abstract}

Ann Fam Med 2013;11:279-281. doi:10.1370/afm.1506.

\section{INTRODUCTION}

$\mathrm{N}$ ow that it seems certain implementation of the US Affordable Care Act (ACA) will continue, the movement to accountable care organizations and patient-centered medical homes will accelerate and increase the emphasis on teams in health care. Policy makers, leaders in health care, and some clinicians expect teams to address the primary care workforce shortages and the challenge of patients with complex, multiple chronic conditions.

Creating effective teams demands the appropriate organizational environment. ${ }^{1-4}$ The information burden, task differentiation, and challenge of meeting the needs of patients provides a strong conceptual justification for teams, and there is evidence they can be effective. ${ }^{5,6}$ Even with explicit efforts to train teams, however, some groups form functional teams and some do not. ${ }^{3}$ Part of the reason for this variation is that organizations control factors affecting teamwork. ${ }^{5}$ Those organizations include primary, secondary, and tertiary care practices, managed care organizations, and potentially the accountable care organizations motivated by the ACA to link those practices. To achieve the high expectations for teams, we need to understand more about how leaders of health care organizations can create environments that support team success. ${ }^{7,3}$

\section{TYPES OF TEAMS}

One of the challenges for leaders is that people discuss teams as if they were a single phenomenon when there are many types of teams. Teams typically are embedded in a larger social system and involve 2 or more 
people who differentiate their roles, share common goals, interact with each other, and perform tasks affecting others. ${ }^{5,8,9} \mathrm{Within}$ this definition, (1) work teams accomplish tasks on an ongoing basis in a specific organizational setting (eg, a primary care team, surgical team, emergency department team); (2) parallel teams address shared challenges, such as responding to a cardiac arrest or aiding the transition of patients from hospital care to ambulatory care, and typically draw participants from several work teams; (3) project teams focus on a one-time deliverable and have limited terms (eg, an electronic health record implementation team); and (4) management teams oversee all the others. ${ }^{5,9,10}$ Some also argue that within work teams there are subcategories whose variation in specialty and disciplinary mix may account for much of their success. ${ }^{5,7}$

Differences among teams are important because the tasks teams undertake, the settings in which they work, and the expectations they face influence their effectiveness. ${ }^{5,10}$ For leaders to help create and support effective teams, they must know what conditions encourage effective functioning of a particular type of team in a particular setting. For example, autonomy may improve outcomes for work teams but may limit project team productivity. ${ }^{9}$ Accordingly, we need to abandon the view of a generic team and move toward an understanding of how leaders create the appropriate environment for the range of team types needed to deliver good care.

\section{SUPPORTING TEAMS}

Primary and subspecialty practice leaders can use current knowledge to address 2 common conditions undermining team success: (1) the lack of training and support for teamwork, and (2) the lack of alignment between incentives and interdependent functions of team members to achieve patient goals. To address the first condition, leaders can work toward creating an organizational culture that values teamwork by encouraging teamwork training to establish important skills ${ }^{11}$ and by emphasizing hiring and promotion based on both team and technical clinical skills. ${ }^{12}$ Leaders can prioritize time for the ongoing coaching that is an important element of team success. ${ }^{3,11}$ Leaders also need to provide time for teams to meet and do teamwork that is not direct medical care, such as reviewing the day's plan. Most importantly, they need to find ways to reimburse or recognize all team members for teamwork.

\section{REIMBURSEMENT}

The challenge of reimbursement for team-based care is a more complex issue and poses a major impediment for organizational leaders. ${ }^{13}$
The reimbursement environment is changing, however, and both policy makers and health care organizational leadership must assure that new metrics and reimbursement reinforce and support the interdependent functions of teamwork. ${ }^{5,6,9,12}$ For example, there are at least 2 teams involved in the care of women due for mammographic screening: the primary care team and the radiology team. Incentives must encourage the interdependent actions among and between both teams to achieve the desired end. National guidelines recommend a discussion of screening mammography before it is ordered for women aged 40 to 49 years. After such a discussion, several more steps in care must take place: the mammogram must be scheduled, the woman must get to the appointment, the mammogram must be performed, the results reported back to the woman, and additional care coordinated if the mammogram findings are abnormal. Traditional health care reimburses the radiologist for doing the mammogram, but currently there are no explicit fees for primary care physicians or their staff to conduct the discussion with women or for the subsequent care coordination. Accountable care organizations could incentivize primary care teams if reimbursement for the discussion and coordination occurred. As long as the reimbursement is not tied to how and with whom the discussion occurs, all those providing primary health care could work with their team to distribute the tasks and use any of the many tools that exist to help women with mammography decisions. The subsequent coordination could also occur by identifying and distributing tasks among team members to assure that results are reported and follow-up occurs. This coordination depends upon communication from the subspecialty team to the primary care team. If accountable care organizations were reimbursed for completed follow-up of abnormal mammograms, there would be an incentive for both the primary and specialty care team. Unfortunately, the appropriate metrics and reimbursement do not exist in the current legislation. Further evidence about how teams can better deliver and coordinate care across the transition between screening and diagnosis could influence policy, however.

\section{CULTIVATING A TEAM ENVIRONMENT}

As leaders wait for our understanding of team functioning to grow, there are some things that they can do now to cultivate an environment for team success. Organizational leaders can do the following:

- Encourage physicians to delegate leadership to others who have the time and skill ${ }^{13,14}$

- Co-locate team members in order to facilitate needed communication ${ }^{15}$ 
- Help teams map their work flow and clarify roles to improve functioning ${ }^{13}$

- Positively influence the culture, composition, and size of teams, all of which affect team outcomes $^{8,12}$

- Involve teams in decisions that affect them, which in turn affects team member loyalty, cooperation, and retention ${ }^{12}$

- Create a culture of safety where medical teams are more likely to reduce medical errors

Teams that perceive they are functioning well implement an increased number of and more fundamental changes in their practices to improve quality. ${ }^{16}$ Feedback from organizational and team leaders shapes, leverages, and aligns team processes and is associated with better outcomes. ${ }^{8,12}$

Leaders also need to adapt to the changes that are on the horizon: (1) the ACA will further motivate the medical home movement and affect the performance of all teams; (2) electronic health records and information technology need to be designed to help rather than hinder teamwork $\mathrm{k}_{i}$ (3) electronic communication can record who is interacting with whom and begin to consider the effect of those interactions on care outcomes; (4) the use of video conferences and remote consultation means we need to evaluate virtual teams and understand how they affect care; and (5) patients are becoming more actively engaged in their own care, so there is a need to explore their role on the health care team. These issues need to be addressed as expectations rise regarding teams' roles in medical homes and health care reform, but organizations must create environments that facilitate teamwork. In addition, we need more research to better understand these environmental influences.

\section{CONCLUSION}

To create environments that support team effectiveness, leaders need to be conscious of their role in shaping teams. Leaders need to recognize that creating effective teams requires their support, coaches who can facilitate the development of teams, organizations that value teamwork, space that encourages teamwork, and leadership that rewards team performance. Health care organizations must learn how to align rewards to support team effectiveness and to provide the resources teams need to succeed.

There are high hopes that teams will bring improvements to care. To ensure their success, leaders need to use what is known about creating the right environment as we continue to learn more about what makes teams effective in health care.
To read or post commentaries in response to this article, see it online at http://www.annfammed.org/content/11/3/279.

Key words: health care delivery; collaboration; health services research; quality of health care; health care teams; health care organizations

Submitted June 28, 2012; submitted, revised, November 26, 2012: accepted December 11, 2012.

Disclaimer: All opinions are those of the authors and cannot be construed to be an endorsement by the Federal Government, the National Cancer Institute, or their respective institutions.

\section{References}

1. Feder JL. A health plan spurs transformation of primary care practices into better-paid medical homes. Health Aff (Millwood). 2011; 30(3):397-399.

2. Iglehart JK. Assessing an ACO prototype-Medicare's Physician Group Practice demonstration. N Engl J Med. 2011;364(3):198-200.

3. Crabtree BF, Nutting PA, Miller WL, Stange KC, Stewart EE, Jaén CR. Summary of the National Demonstration Project and recommendations for the patient-centered medical home. Ann Fam Med. 2010;8(Suppl 1):S80-S90, S92.

4. Ghorob A, Bodenheimer T. Sharing the care to improve access to primary care. N Engl J Med. 2012;366(21):1955-1957.

5. Lemieux-Charles L, McGuire WL. What do we know about health care team effectiveness? A review of the literature. Med Care Res Rev. 2006;63(3):263-300.

6. Poole CA, Byers T, Calle EE, Bondy J, Fain P, Rodriguez C. Influence of a family history of cancer within and across multiple sites on patterns of cancer mortality risk for women. Am J Epidemiol. 1999;149(5):454-462.

7. Poole MS, Real K. Groups and teams in health care: communication and effectiveness. In: Thompson TL, Dorsey AM, Miller Kl, Parrott $\mathrm{R}$, eds. Handbook of Health Communication. Mahwah, NJ: Lawrence Erlbaum Associates; 2003:369-402.

8. Fried B. TSEA. Teams and team effectiveness in health services organizations. In: Burns LR, Bradley E, Weiner BJ, eds. Shortell \& Kaluzny's Health Care Management; Organization Design \& Behavior. Clifton Park, NJ: Delmar, Cengage Learning; 2012.

9. Cohen SG, Bailey DE. What makes teams work: group effectiveness research from the shop floor to the executive suite. J Manage. 1997;23:239-289.

10. Mathieu JM, Maynard TM, Rapp T, Gilson L. Team effectiveness 1997-2007: a review of recent advancements and a glimpse into the future. J Manage. 2008;34:410-476.

11. Salas E, Weaver SJ. DiazGranados D, Lyons R, King H. Sounding the call for team training in health care: some insights and warnings. Acad Med. 2009;84(10 Suppl):S128-S131.

12. West MA, Guthrie JP, Dawson JF, Borrill CS, Carter M. Reducing patient mortality in hospitals: the role of human resource management. J Organiz Behav. 2006;27:983-1002.

13. Grumbach K, Bodenheimer T. Can health care teams improve primary care practice? JAMA. 2004;291(10):1246-1251.

14. Crabtree BF, McDaniel RR, Nutting PA, Lanham HJ, Looney AJ, Miller WL. Closing the physician-staff divide: a step toward creating the medical home. Fam Pract Manag. 2008;15(4):20-24.

15. Ghorob A, Bodenheimer T. Share the Care: building teams in primary care practices. J Am Board Fam Med. 2012;25(2):143-145.

16. Shortell SM, Marsteller JA, Lin M, et al. The role of perceived team effectiveness in improving chronic illness care. Med Care. 2004;42(11):1040-1048. 